\title{
Statistical Modeling of Farmers' Preference for Adaptation Strategies for Climate Change: The Case of Dera District, Oromia, Ethiopia
}

\author{
Tadesse Ayele Belachew (iD ${ }^{1}$ and Dereje Gebeyehu Ababu ${ }^{2}$ \\ ${ }^{1}$ Department of Statistics College of Natural Science, Salale University, Fiche, Ethiopia \\ ${ }^{2}$ Department of Statistics College of Natural Science, Mettu University, Mettu, Ethiopia \\ Correspondence should be addressed to Tadesse Ayele Belachew; tadeayele2003@gmail.com
}

Received 19 October 2020; Revised 26 February 2021; Accepted 9 March 2021; Published 20 March 2021

Academic Editor: John Mburu

Copyright (C) 2021 Tadesse Ayele Belachew and Dereje Gebeyehu Ababu. This is an open access article distributed under the Creative Commons Attribution License, which permits unrestricted use, distribution, and reproduction in any medium, provided the original work is properly cited.

\begin{abstract}
Climate change is primarily detrimental to the agriculture sector and the influence of climate change is decreased by using appropriate adaptation strategies. Studies on climate change adaptation recognize the importance of specific area-based research for designing policies to respond to climate change. This study, therefore, was applied at the district level to examine farmers' preference for climate change adaptation strategies and the factors determining their preference. The objective of this study is to identify and model factors that influence farmers' preference of adaptation strategies to counter the impacts of climate change in the case of Dera District, North Shoa, Oromia, Ethiopia. Cross-sectional study design was used with the questionnaire being administered on a multistage sample of 460 households from selected kebeles in the district. Descriptive statistics, multinomial logit, and count regression analysis were used to analyze the collected data. The study revealed that the farmers perceived that temperature had been increasing and rainfall had been decreasing over the last 10 years. The results also indicated that planting trees was the most preferred and frequently applied adaptation strategy to climate change while changing planting dates was the least. The results from the multinomial logit, Poisson regression, and negative binomial analysis showed that age, source of information, household size, education level of household head, distance to output market, distance to input market, agroecological locations of the farm, tropical livestock unit, size of the farm, tenure, grade of the farm, distance of the farm, formal extension service, farmer-to-farmer extension, credit service, rainfall expectation, and temperature expectations were significant factors in determining the adaptation strategies preferred by the farmers.
\end{abstract}

\section{Introduction}

Climate change is a long-term shift in the statistics of weather (including its averages) for a given place and time. Article 1 of the United Nation Framework Convention on Climate Change (UNFCCC) [1] defines climate change as a change of climate which is attributed directly or indirectly to human activity that alters the composition of the global atmosphere and which is in addition to natural climate variability observed over comparable periods that is being experienced globally in various forms such as temperature rise, droughts, floods, hurricanes, landslides, etc. Climate change is a hot issue affecting the livelihoods and food security in both developing and developed countries.
Accordingly, climate variability and change are among the major environmental challenges of the twenty-first century [2].

Agriculture places a heavy burden on the environment in the process of providing humanity with food and fiber, while climate is the primary determinant of agricultural productivity. Interest in this issue has motivated a substantial body of research on climate change, and agriculture over the past decade [3]. Climate change is expected to influence crop and livestock production, hydrologic balances, input supplies, and other components of agricultural systems. Due to these, climate change has been recognized globally as the most pressing critical issue affecting mankind's survival in the twenty-first century. 
Climate change adaptation is the process of adjustment to actual or expected climate and its effects. In human systems, adaptation seeks to moderate or avoid harm or exploit beneficial opportunities in response to actual or expected climatic stimuli or their effects [4]. Adaptation is identified as one of the policy options to reduce the negative impact of climate change [5]. Therefore, adaptation is critical and of concern in developing countries, particularly in Africa where vulnerability is high because the ability to adapt is low [6].

Ethiopia is one of the African countries with a low capacity to adapt to climate change and the Ethiopian economy is dominated by subsistence agriculture which is characterized by small-scale farming and livestock husbandry at the expense of deforestation and with the subsequent decline of soil fertility resulting in decreased land productivity. The sector directly supports about $85 \%$ of the population in terms of employment and livelihood, contributes about $40 \%$ of the country's gross domestic product (GDP), generates about $88 \%$ of the export earnings, and supplies around $73 \%$ of the raw material requirement of agro-based domestic industries and approximately $80 \%$ of households live in rural areas and are dependent on local agriculture to meet their food needs. Also besides, agriculture is expected to play a key role in generating surplus capital to speed up the country's overall socioeconomic development [7].

Despite its high contribution to the overall economy, this sector is challenged by many factors, of which climaterelated disasters like drought and flood (often causing famine) are the major ones [8]. In addition to the naturedependent agricultural sector of the economy, the country's geographical location and topography in combination with low adaptive capacity can cause a high vulnerability to adverse impacts of climate change. In general, climate change is one of the main challenging factors that determine the agricultural sector's contribution to the national economy.

Furthermore, climate change adaptation policy and program design need to consider the specific characteristics of every place and community. Because adaptation is often conceptualized as a site-specific phenomenon, many authors call for more local-level analyses to gain a better understanding of the fundamental processes underlying adaptation and for better targeting of adaptation policies [9]. That means measures or interventions at the local or micro level are important and feasible in the reduction of climate change impact on farmers in a certain area. According to the findings of Tesso et al. [10], the districts in North Shewa of Oromia are largely affected by the negative impacts of climate change. Therefore, this research would contribute solutions to these pressing problems by identifying and analyzing the determinants of farmers' preference for adaptation strategies to the impacts of climate change in this area and model each adaptation option. To sum up, this study is aimed at modeling adaptation preference and analyzing the determinants of farmers' preference for adaptation strategies to mitigate the impacts of climate change in the study area.

\section{Methodology}

2.1. Location of the Study Area. Dera is one of the districts in the North Showa Zone, Oromia Region of Ethiopia, which is located $220 \mathrm{~km}$ north of Addis Ababa, the capital city of Ethiopia, with an area of 160315 hectares. The district is bordered on the south by the Jemma River which separates it from Hidhabu Abote, and Wara Jarso, on the west, north and east by the Amhara region; the Abay River defines the western boundary, and its tributary Walaka River defines the northern boundary. The district is located between $10^{\circ} 2^{\prime}-10^{\circ} 35^{\prime} \mathrm{N}$ latitude and $38^{\circ} 20^{\prime}-38^{\circ} 50^{\prime} \mathrm{E}$ longitude and elevation from $1798 \mathrm{~m}$ to $2118 \mathrm{~m}$ above sea level.

2.2. Types and Source of Data. Both primary and secondary data were collected for this study depending on the nature and availability of data.

2.2.1. Methods of Data Collection. The data collection was carried out using structured questionnaires filled by data collectors.

(1) Sampling Techniques. The ultimate goals of sampling techniques are to select a set of representative elements from the population, to yield maximum precision per unit cost with great accuracy and to solve the problem of bias. To achieve these goals, the researcher used multistage stage random sampling. This means there were two stages of sampling. In the first stage, by using the frame of the kebeles (neighborhoods), samples of kebeles were selected (primary sampling units). Finally, a simple random sampling was employed to get a representative sample of households from the selected kebeles.

(2) Sample Size Determination. Appropriate sample size depends on various factors relating to the subject under investigation like: time, cost, degree of accuracy, the variability of the population, objective of research, etc. Based on the above information, there are several formulas developed for sample size calculation that conform to different research situations. Accordingly, single population proportion formula was adopted for this study and desired sample size for the study is 460 . The data were collected from the selected 460 households by using the questionnaire method.

2.2.2. Methods of Data Analysis. The data were analyzed using different statistical software. To analyze the data, descriptive and inferential statistics were used. Descriptive analyses were used to describe the percentages and number distributions of the respondents by sociodemographic characteristics. Furthermore, inferential statistics, specifically multinomial logistic regression analysis and count regression model were used to identify factors that affect the adaptation strategy of farmers to climate change.

(1) Multinomial Logistic Regression Analysis. Multinomial logistic regression is a technique that fits multiple logistic regressions on a multi-category unordered response variable 
that has been dummy-coded [11]. Multinomial logistic regression is often considered an attractive analysis because it does not assume normality, linearity, or homoscedasticity.

To describe the MNL model, we assume that each farmer prefers a set of discrete, mutually exclusive choices of adaptation measures (that means that a person chooses exactly one of the options, not more and not less). Let $Y_{i}$ denote adaptation measures taken by households taking on the values $\{1,2, \ldots, J\}$ where $J$ is a positive integer and $X_{i}$ represents a number of climate attributes, environmental, socioeconomic characteristics of households, and other factors. Then to construct the logits in the multinomial case, one of the categories must be considered the base level, and all the logits are constructed relative to it. Any category can be taken as the base level, so this study considers category $J$ as the baseline-category. Let $P_{i j}$ denote the multinomial probability of an observation $i$ falling in the $j^{\text {th }}$ category. Then,

$$
\begin{aligned}
& P_{i j}=P\left(y=\frac{j}{x_{i}}\right)=\frac{\exp \left(X_{i}^{T} \beta_{j}\right)}{1+\sum_{h=1}^{J-1} \exp \left(X_{i}^{T} \beta_{h}\right)}, \text { taking } J^{\text {th }} \text { category as baseline - category, } \\
& P_{i}=J(\text { for baseline }- \text { category })=P\left(y=\frac{j}{x_{i}}\right)=\frac{1}{1+\sum_{h=1}^{J-1} \exp \left(X_{i}^{T} \beta_{h}\right)},
\end{aligned}
$$

where $h=1,2, \ldots, J-1$, and $J$ is the number of categories of the dependent variable.

Multinomial logistic regression is a technique that fits multiple logistic regressions on a multi-category unordered response variable forming $J-1$ nonredundant logit. By taking the $J^{\text {th }}$ category as a reference category, the multinomial logistic regression is given as follows.

$$
\log i t\left[\frac{P\left(Y=j / \mathbf{X}_{i}\right)}{P\left(Y=J / \mathbf{X}_{i}\right)}\right]=\beta_{j 0}+\beta_{j 1} x_{l i}+\cdots+\beta_{j k} x_{k i}=X_{i}^{T} \beta_{j}
$$

where $\mathbf{X}$ is vector of independent variables having dimension of $k+1, j=1, \ldots, J-1$,

$$
\beta_{1}=\left[\begin{array}{c}
\beta_{10} \\
\beta_{11} \\
\cdot \\
\cdot \\
\cdot \\
\beta_{1 k}
\end{array}\right], \beta_{2}=\left[\begin{array}{c}
\beta_{20} \\
\beta_{21} \\
\cdot \\
\cdot \\
\cdot \\
\beta_{2 k}
\end{array}\right], \ldots \beta_{j}=\left[\begin{array}{c}
\beta_{j 0} \\
\beta_{j 1} \\
\cdot \\
\cdot \\
\cdot \\
\beta_{j k}
\end{array}\right]
$$

(2) Assumptions of Multinomial Logistic Regression. The multinomial logit is used to model choices; it relies on the assumption of independence of irrelevant alternatives (IIA). This assumption states that the odds of preferring one class over another do not depend on the presence or absence of other "irrelevant" alternatives. This allows the choice of $J$ alternatives to be modeled as a set of J-1 independent binary choices, in which one alternative is chosen as a "pivot" and the other $J-1$ is compared against it, one at a time. Hausman and McFadden (1984) proposed a Hausman-type test of this hypothesis. This involves the following steps.

(1) Estimate the full model with all $J$ outcomes included; these estimates are contained in $\beta_{F}$.

(2) Estimate a restricted model by eliminating one or more outcome categories; these estimates are contained in $\beta_{R}$.
(3) Let $\beta_{F}{ }^{*}$ be a subset of $\beta_{F}$ after eliminating coefficients not estimated in the restricted model. The Hausman test of IIA is defined as

$$
H_{\mathrm{IIA}}=\left(\beta_{R}-\beta_{F}^{*}\right)^{\prime}\left[\operatorname{Var}\left(\beta_{R}\right)-\operatorname{Var}\left(\beta_{F}^{*}\right)\right]-1\left(\beta_{R}-\beta_{F}^{*}\right),
$$

where $H_{\text {IIA }}$ is asymptotically distributed as chi-square with degrees of freedom equal to the rows in $\beta_{R}$ if IIA is true. Significant values of $H_{\text {IIA }}$ indicate that the IIA assumption has been violated. Hausman and McFadden noted that the $H_{\text {IIA }}$ can be negative when $\operatorname{Var}\left(\beta_{R}\right)-\operatorname{Var}\left(\beta_{F}{ }^{*}\right)$ is not positive semidefinite and suggested that a negative $H_{\text {IIA }}$ is an evidence that IIA holds.

(3) Estimation of Coefficients in the Multinomial Logistic Regression Model. The general method of estimating logistic regression parameters is called maximum likelihood. The method of maximum likelihood yields values for the unknown parameters which maximize the probability of obtaining the observed set of data. To apply this method, we first construct a function, called the likelihood function. This function expresses the probability of the observed data as a function of the unknown parameters. The maximum likelihood estimators of these parameters are chosen to be those values that maximize this function. Thus, the resulting estimators are those which agree most closely with the observed data. To find the maximum likelihood estimators for multinomial distribution, define the likelihood function as follows:

$$
L\left(\frac{y}{\beta}\right)=\prod_{i=1}^{n}\left[\frac{n_{i j}}{\prod_{j=1}^{J} y_{i j} !} \prod_{j=1}^{J} \pi i j^{y_{i j}}\right] .
$$

Since we want to maximize equation (5) with respect to $\beta$, the factorial terms that do not contain any of the $\pi i j$ terms can be treated as constants. Thus, the likelihood function for multinomial logistic regression models is 


$$
L\left(\frac{y}{\beta}\right) \simeq \prod_{i=1}^{n}\left[\prod_{j=1}^{J} \pi i j^{y_{i j}}\right] .
$$

By distributing the product term in equation (6), we get

$$
\begin{aligned}
L\left(\frac{y}{\beta}\right) & =\prod_{i=1}^{n}\left[\prod_{j=1}^{J} \pi i j^{y_{i j}} \cdot \pi i J^{y_{i J}}\right] . \\
\text { Let } \sum_{j=1}^{J} y_{i j} & =n_{i} \text {, then } y_{i J}=n_{i}-\sum_{j=1}^{J-1} y_{i j} .
\end{aligned}
$$

Substituting $y_{i J}$ in equation (7) yields

$$
L\left(\frac{y}{\beta}\right)=\prod_{i=1}^{n}\left[\prod_{j=1}^{J} \pi i j^{y_{i j}} \cdot \pi i J^{n_{i}-\sum_{j=1}^{j-1} y_{i j}}\right]=\prod_{i=1}^{n}\left[\prod_{j=1}^{J-1}\left(\frac{\pi i j}{\pi i J}\right)^{y_{i j}} \cdot \pi_{i j}^{n_{i}}\right] .
$$

By rearranging equation (9) and substituting $\pi_{i j}=(\exp$ $\left.\left(X_{i}^{T} \beta_{h}\right)\right) /\left(1+\sum_{h=1}^{J-1} \exp \left(X_{i}^{T} \beta_{h}\right)\right)$ and $\pi_{i J}=1 /\left(1+\sum_{h=1}^{J-1} \exp \right.$ $\left.\left(X_{i}^{T} \beta_{h}\right)\right)$, we get

$$
L\left(\frac{y}{\beta}\right)=\prod_{i=1}^{n}\left[\prod_{j=1}^{J-1}\left(\exp \left(X_{i}^{T} \beta_{j}\right)\right)^{y_{i j}} \cdot\left(\frac{1}{1+\sum_{h=1}^{J-1} \exp \left(X_{i}^{T} \beta_{h}\right)}\right)^{n_{i}}\right] .
$$

Taking the natural log of equation (10) gives us the loglikelihood function for the multinomial logistic regression model:

$$
L(\beta)=\sum_{i=1}^{n}\left(\sum_{j=1}^{J-1}\left(X_{i}^{T} \beta_{h}\right) y_{i j}-n_{i} \log \left(1+\sum_{j=1}^{J-1} \exp \left(X_{i}^{T} \beta_{h}\right)\right)\right) .
$$

The maximum likelihood estimates are the values for $\beta$ that maximize the likelihood function in equation (11). But the equation is nonlinear in $\beta$, and as a result, the estimates do not have a closed-form expression. Therefore, $\beta$ were obtained by using the iterative algorithm method (Agresti, 1996).

(4) Introduction to Poisson and Negative Binomial Regression Model. Poisson regression is one of the most popular techniques for regression with count data. Poisson regression assumes a Poisson distribution, characterized by a substantial positive skewness with variance equal to mean. More realistically, mean and variance may vary due to unexplained/unmeasured/factors. However, if the variance is larger than the mean, it induces deflated standard errors and inflated standardized normal values, resulting in increased Type I errors that make Poisson regression less adequate.

Assumptions of Poisson distribution:

(1) The probability of observing a single event over a small interval is approximately proportional to the size of that interval.

(2) The probability of an event within a certain interval does not change over different intervals.
(3) The probability of an event in one interval is independent of the probability of an event in any other non-overlapping interval.

If either of these last two assumptions is violated, they can lead to over-dispersion. The negative binomial (NB) regression model is a direct extension of the Poisson model that allows for over-dispersion. Negative binomial regression model is simply a Poisson regression that estimates the dispersion parameter, allowing for the independent specification of the mean and variance. This study reviewed two modeling strategies for count data: basic Poisson models if there is no over-dispersion and negative binomial for count data with some evidence of over-dispersion. If the overdispersion results from a high frequency of zero counts, advanced composite models such as Hurdle regression, ZIP regression, and Latent Class regression might give a more satisfactory fit to the data.

(5) Variables Included in the Study. The dependent variable was preference (first choice) of adaptation strategies taken by farmers to adapt impact of the climate changes. The following five adaptation options have been selected for this study: using different enterprises (different crops or livestock), different planting dates, planting trees, soil-water conservation techniques, and no adaptation. Independent variables are variables that determine the preference of adaptation strategies of farmers to climate change. These include Age (age of household head), Sex (sex of household head), Educleve (education level of household head), Sourcein (source of information), Hhsize (household size), Agroecol (agroecological location of the farm), Sizeoffa (farm size), Tlu (number of livestock), the distance (distance to input market), Distancb (distance to output market), distanc1 (distance of farm from the house), irrigati (access irrigation service), ownershi (land ownership), Gradeoff (grade of the farm), extension (access extension services by experts), farmerto (farmer-to-farmer extension services), credit (credit services), tempera0 (temperature expectation), and rainexp (rainfall expectations). The coding and explanation of variables in the model are discussed in Appendix 1 Table 1.

\section{Results and Discussion}

3.1. Descriptive Results. The actual adaptation measures preferred by farmers are $44.2 \%, 29.1 \%, 9.3 \%$, and $9.8 \%$ of the respondent preferred planting trees, using different enterprises, changing planting dates, and SWC, respectively. The remaining $7.6 \%$ of the respondent did not select any adaptation measure presented for them. Generally, planting trees and using different enterprises were the most highly preferred adaptation strategies to climate change by the farmers in the study area, while SWC and changing planting dates were the least preferred adaptation strategies.

3.1.1. Test of Association between Adaptation Strategies and the Independent Variable. From chi-square test of association between adaptation strategy preference and 
explanatory variables, sex of head of household, age of household head, household educational level, source of information, household size, distance of sell, distance of buy, agroecology, tropical livestock unit, size of the farm, tenure, grade of a farm, distance of the farm, extension service, farmer-to-farmer extension, credit, irrigation, rainfall expectation, and temperature expectation were found significant at 5\% level of significance (Appendix 1; Table 2).

3.2. The Multinomial Logistic Regression Analysis. Table 1 shows that $46.5 \%, 91.4 \%, 97.5 \%, 84.4 \%$, and $91.8 \%$ of households who preferred changing planting dates, no adaptation, planting trees, soil-water conservation techniques, and using different enterprises, respectively, were predicted correctly in the multinomial logistic regression model for adaptation strategies. $89.3 \%$ overall correct prediction was obtained by using the multinomial logistic regression model.

Assumption of independent irrelevant alternative was tested using Hausman test as follows.

As presented in Table 2, the chi-square result for all tests ranges from -5.24 to 38.5 , with probability values ranging from 0.9988 to 1.0000 . One of the test statistics was negative which was common in such tests and was evidence that IIA was not violated. This possibility was also noted by Long and Freese [12] and Hausman and McFadden (1984). This suggests that the multinomial logistic regression model specified in this research is appropriate for modeling farmers' preferences for climate change adaptation strategies.

3.3. Results of Multinomial Logistic Regression Analysis. The result revealed that age of household head, source of information, household size, education level of household head, distance of output market, a distance of input market, agroecological location of the farm, tropical livestock unit, size of the farm, tenure, grade of the farm, distance the farm, extension service, farmer-to-farmer extension, credit service, rainfall expectation, and temperature expectation were significant factors that affect overall adaptation preference of farmers to climate change at 5\% level of significance (Appendix 1 Table 3). Multinomial logistic regression analysis revealed the odds of each adaptation strategy relative to the reference category (no adaptation) as discussed hereafter.

3.3.1. Using Different Enterprises (UDV) Relative to No Adaptation. Controlling other variables in the model, the odds of using different enterprises relative to no adaptation were 4.7 times higher among households who got information from media as compared to households with no information. Similarly, the odds of using different enterprises relative to no adaptation were 4.3 times higher for households who got information from social groups as compared to households with no information.

Holding other variables in the model, the odds of households using different enterprises relative to no adaptation were increased by $1.16,4.16,1.51$, and 2.78 times for a unit increase of age, household size, number of livestock, and size of the farm, respectively. Similarly, the odds of households using different enterprises relative to no adaptation decreased by $0.78,0.82$, and 0.75 times for a unit increase of the distance of output market, the distance of input market, and the distance of the farm, respectively. Holding other variables in the model constant, the odds of using different enterprises relative to no adaptation were 6.71 times higher among households who got extension service as compared households who did not get extension service. The odds of using different enterprise relative to no adaptation were 1.16 times higher for households who got the farmer-to-farmer extension service as compared to households who did not get farmer-to-farmer extension. Similarly, odds of using different enterprises compared to no adaptation were 6.91 times higher for households who had their farm as compared to households who did not have their farm.

The odds of using different enterprises relative to no adaptation were 3.51 times higher for households from dega as compared to households from kola. Similarly, the odds of using different enterprises relative to no adaptation were 4.94 times higher for households from weinadega as compared to households from kola. Keeping other variables in the model constant, the odds for using different enterprises compared to no adaptation were 0.029 times lower among households with $B$ grade of the farm as compared to households with A grade of the farm. Similarly, the odds for using different enterprises relative to no adaptations were 0.012 times lower among households with $\mathrm{C}$ grade of the farm as compared to households with $\mathrm{A}$ grade of the farm.

The odds of using different enterprises relative no adaptation were 4.16 times higher among households whose future expectation was a change in temperature as compared to households whose future expectation was no change in the temperature. Similarly, the odds of households for using different enterprises relative no adaptation were 5.38 times higher among households whose future expectation was a change in rainfall as compared to households whose future expectation was no a change in rainfall, holding other variables in the model constant.

3.3.2. Changing Planting Dates (CPD) Relative to No Adaptation. The odds of changing planting dates relative to no adaptation were 6.39 times higher for households who got information from media as compared to households who did not get any information. Similarly, the odds of changing planting dates relative to no adaptation were 4.03 times higher for households who got information from social groups compared to households who did not get any information, holding the other variable in the model constant. The odds of households changing planting dates relative to no adaptations were increased by 1.12 and 2.80 times for a unit increase of age, size of the farm. Similarly, the odds of households changing planting dates relative to no adaptation were decreased by $0.86,0.79$, and 0.71 times for a unit increase the distance of output market, the distance of input market, and distance of farm, respectively. 
Table 1: Classification Table. Assumption of independent irrelevant alternative (IIA).

\begin{tabular}{|c|c|c|c|c|c|c|}
\hline \multirow{2}{*}{ Observed } & \multicolumn{6}{|c|}{ Predicted } \\
\hline & $\mathrm{CPD}$ & No adapt & PT & SWC & UDV & Percent correct $(\%)$ \\
\hline Changing planting dates (CPD) & 20 & 0 & 4 & 1 & 18 & 46.5 \\
\hline No adaptation & 0 & 32 & 3 & 0 & 0 & 91.4 \\
\hline Planting trees $(\mathrm{PT})$ & 0 & 1 & 198 & 3 & 1 & 97.5 \\
\hline Soil-water conservation (SWC) & 2 & 0 & 3 & 38 & 2 & 84.4 \\
\hline Using different enterprises(UDV) & 4 & 2 & 2 & 3 & 123 & 91.8 \\
\hline Overall percentage $(\%)$ & 5.7 & 7.6 & 45.7 & 9.8 & 31.3 & 89.3 \\
\hline
\end{tabular}

TABle 2: Hausman-McFadden test of IIA assumption.

\begin{tabular}{|c|c|c|c|c|}
\hline Omitted categories & Chi-square & Degree of freedom & $P>$ chi & Evidence \\
\hline Using different enterprises & 26.10 & 78 & 0.9999 & Support HO \\
\hline Different planting dates & 11.10 & 78 & 1.0000 & Support HO \\
\hline Planting trees & -5.24 & 78 & & Support HO \\
\hline SWC & 38.5 & 78 & 0.9988 & Support HO \\
\hline
\end{tabular}

The odds of changing planting dates compared to no adaptation were 7.38 times higher among households who got the extension service as compared to households who did not get extension. Similarly, the odds of changing planting dates relative to no adaptation were 4.64 times higher for households who got the farmer-to-farmer extension service as compared to households who did not get farmer-to-farmer extension, keeping other variables in the model constant. The odds of changing planting dates compared to no adaptation were 1.26 times higher among households from dega as compared to households from kola. The odds of changing planting dates relative to no adaptation were 1.18 times higher among households from weinadega as compared to households from kola.

The odds of changing planting dates compared to no adaptation were 0.030 times lower among households with B grade of the farm as compared to households with A grade of the farm. Similarly, the odds of changing planting dates relative to no adaptation were 0.048 times lower for households with $\mathrm{C}$ grade of the farm as compared to household with A grade, holding other variables in the model constant. The odds for changing planting dates compared to no adaptation were 6.12 times higher for households whose future expectations changed in temperature as compared to the households whose future expectations were no change in temperature. The odds of changing planting dates relative no adaptation were 5.31 times higher for households whose future expectations were change in rainfall as compared to the households whose future expectations were no change in rainfall, holding other variables in the model constant.

3.3.3. Planting Trees (PT) Relative to No Adaptation. Holding other variables in the model constant, the odds of planting trees relative to no adaptation were increased by 2.40 and 2.24 times for a unit increase of the size of the farm and household size, respectively. The odds of planting trees relative to no adaptation decreased by $0.88,0.91$, and 0.77 times for a unit increase in distance of input market, age of household head, and distance of the farm, respectively. The odds of planting trees relative to no adaptation were 1.27 times higher among households who got information from media as compared to households with no information. Similarly, the odds of planting trees relative to no adaptation were 1.28 times higher among households who got information from social groups as compared to households with no information. The odds of planting trees relative to no adaptation were 4.95 times higher among households whose head has primary education as compared to those households with illiterate household head, holding other variables in the model constant.

The odds of planting trees relative to no adaptation were 7.50 times higher for households who got extension service as compared to households who did not get extension. Odds of planting trees relative to no adaptation were 7.20 times higher for households who got farmer-to-farmer extension service as compared to households who did not get farmerto-farmer extension. Holding the variables in the model constant, the odds of planting trees relative to no adaptation were 3.78 times higher for households from dega as compared to households from kola. The odds of planting trees compared to no adaptation were 6.87 times higher for households from weinadega as compared to households from kola.

The odds of planting trees relative to no adaptation were 5.05 times higher for households whose future expectation was change in temperature as compared households whose future expectation was no change. Similarly, the odds of planting trees relative to no adaptation were 7.77 times higher for households whose future expectation was change in rainfall as compared to households whose future expectation was no change in rainfall, holding other variables in the model constant.

3.3.4. Soil-Water Conservation (SWC) Techniques Relative to No Adaptation. Holding other variables in the model constant, the odds of preferring SWC techniques relative to no adaptation were increased by 1.24 and 1.34 for a unit increase in household size and number of livestock, respectively. The odds of households preferring SWC 
techniques relative to no adaptation decreased by 0.78 and 0.62 times for a unit increase in distance of farm and distance of input market, respectively. The odds of preferring SWC relative to no adaptation were 1.18 times higher for households who got information from social groups as compared to households who did not get any information. Similarly, the odds of preferring SWC relative to no adaptation were 1.13 times higher for households who got information from media as compared to households who did not get any information from any source, holding other variables in the model constant.

Holding other variables in the model constant, the odds of preferring SWC techniques relative to no adaptation were 4.83 times higher among households whose head has primary school education level as compared to households with illiterate household head. Similarly, the odds of preferring SWC techniques relative to no adaptation were 4.59 times higher for households whose head has high school and above education level as compared to households with illiterate household head. The odds of preferring SWC compared to no adaptation were 4.28 times higher for households from dega as compared to households from kola. Similarly, the odds of preferring SWC relative to no adaptation were 5.16 times higher for households from weinadega as compared to households from kola.

The odds of preferring SWC techniques relative to no adaptation were 0.049 times lower for households with B grade of farm as compared to households with A grade of farm. The odds of preferring SWC compared no adaptation were 3.24 times higher for households who got extension service as compared to households who did not get extension. Similarly, the odds of preferring SWC relative to no adaptation were 1.26 times higher for households who had access to credit service as compared to households who did not have access to credit service.

Holding other variables in the model constant, the odds of preferring SWC techniques relative to no adaptation were 4.69 times higher for households whose future expectation was change in temperature as compared to households whose future expectation was no change in temperature. The odds for preferring SWC techniques relative to no adaptation were 5.09 times higher among households whose future expectation was change in rainfall as compared to households whose future expectation was no change in rainfall.

\subsection{Determinants of Adaptation Strategy Using Count Re-} gression Model. Based on fit statistics discussed in Table 3 for the Poisson model, the Pearson chi-square and deviance values divided by the degrees of freedom are less than one. But for the negative binomial model, both the Pearson chisquare and deviance ratios are greater than one. Therefore, Poisson regression model is the best model for using different enterprise. Following the same approaches, negative binomial regression for changing planting dates and watersoil conservation techniques, and Poisson regression model for planting trees are best fit models.
3.4.1. Results of Poisson Regression and Negative Binomial Analysis. We now fit the Poisson regression model for modeling using different enterprises and planting trees and negative binomial regression model for modeling changing planting dates and water-soil conservation techniques. It is reasonable to assess the magnitude of the effect of several factors acting jointly over and above their effects considered separately. In other words, the extent to which the effect of one factor changes for different values of one or more other factors (interactions effect) needs to be measured. The significance of the interaction effects was looked at by adding them into the main effects model one at a time. According to our results, two-way interaction effects were found to be insignificant. However, three-way and above interactions were not incorporated in the model because the inclusion of these terms introduces complexity to the analysis and interpretation of results. Therefore, no interactions are included in the analysis.

3.4.2. Using Different Enterprises (UDV). The statistical tests of significance of individual coefficient of using different enterprises indicators are based on Wald Chi-square and $P$ value of respective coefficients as shown in Appendix 1 Table 4. The result revealed that age of household head, source of information, household size, distance of output market, distance of input market, agroecological location of the farm, size of the farm, number of livestock, grade of the farm, distance of the farm, extension service, credit service, farmer-to-farmer extension, rainfall expectation, and temperature expectation were significant factors affecting using different enterprises as adaptation options to climate change at $5 \%$ level of significance. The Poisson regression analysis revealed the following result for using different enterprises as adaptation option. Holding the other variables in the model constant, the odds of using different enterprises were increased by factor of $1.016,1.02,1.04$, and 1.036 for a unit increase of age of household head, number of livestock, household size, and size of the farm, respectively. The odds of households using different enterprises were decreased by a factor of $0.97,0.99$, and 0.98 , for a unit increase in distance of input market, distance of output market, distance of farm, respectively, holding other variables in the model constant.

Households who got information from media were about 1.26 times more likely to use different enterprise and households who got information from social group were about 1.218 times more likely to use different enterprise as compared to households with no information. Similarly, households whose farms are located in dega and kola were about 1.386 and 1.357 times, respectively, more likely to use different enterprise than households who have farm from kola, keeping other variables in the model constant. Regarding grade of farm, households with $\mathrm{B}$ and $\mathrm{C}$ grade of farm were less likely to use different enterprise (0.88 times and 0.79 times, respectively) as compared to households with A grade of farm.

Households that got extension service were about 1.18 times more likely to use different enterprise compared to households who did not have extension service. Households 
TABLe 3: Test for goodness of fit between Poisson and negative binomial regression models.

Using different enterprise

\begin{tabular}{|c|c|c|c|}
\hline Criteria & Estimate & Poisson regression & Negative binomial regression \\
\hline \multirow{2}{*}{ Deviance } & Values & 273.316 & 1124.647 \\
\hline & Values/df & 0.630 & 2.591 \\
\hline \multirow{2}{*}{ Pearson chi-square } & Values & 200.599 & 997.179 \\
\hline & Values/df & 0.462 & 2.298 \\
\hline \multicolumn{4}{|c|}{$\begin{array}{l}\text { Likelihood-ratio test of alpha }=0 \text { : chibar } 2(01)=0.00 \text { Prob } \geq \text { chibar } 2=1.000 \\
\text { Changing planting dates }\end{array}$} \\
\hline Criteria & Estimate & Poisson regression & Negative binomial regression \\
\hline \multirow{2}{*}{ Deviance } & Values & 1157.392 & 273.143 \\
\hline & Values/df & 2.667 & 0.629 \\
\hline \multirow{2}{*}{ Pearson chi-square } & Values & 943.677 & 164.838 \\
\hline & Values/df & 2.174 & 0.380 \\
\hline \multicolumn{4}{|c|}{ Likelihood-ratio test of alpha $=0$ : chibar $2(01)=355.42$ Prob $\geq$ chibar $2=0.0001$} \\
\hline \multicolumn{4}{|l|}{ Planting tree } \\
\hline Criteria & Estimate & Poisson regression & Negative binomial regression \\
\hline \multirow{2}{*}{ Deviance } & Values & 334.141 & 1447.651 \\
\hline & Values/df & 0.770 & 3.336 \\
\hline \multirow{2}{*}{ Pearson chi-square } & Values & 209.856 & 1205.479 \\
\hline & Values/df & 0.484 & 2.778 \\
\hline \multicolumn{4}{|c|}{ Likelihood-ratio test of alpha $=0$ : chibar $2(01)=0.00$ Prob $\geq$ chibar $2=1.000$} \\
\hline \multicolumn{4}{|c|}{ Soil-water conservation technique } \\
\hline \multirow{2}{*}{ Deviance } & Values & 1962.703 & 590.838 \\
\hline & Values/df & 4.522 & 1.361 \\
\hline \multirow{2}{*}{ Pearson chi-square } & Values & 1825.101 & 432.890 \\
\hline & Values/df & 4.205 & .997 \\
\hline \multicolumn{4}{|c|}{ Likelihood-ratio test of alpha $=0$ : chibar $2(01)=355.42$ Prob $>$ chibar $2=0.0001$} \\
\hline
\end{tabular}

who had access to credit were about 0.9 times less likely to use different varieties relative to households who did not have access to credit. Households who got farmer-to-farmer extension service were about 1.24 times more likely to use different enterprise compared to households who did not have farmer-to-farmer extension service, given that other variables in the model were held constant.

Regarding future expectation of climate change, the odds of using different enterprises were about 1.2 times higher for those households whose future expectation was change in temperature as compared households who did not expect any change. Similarly, households whose future expectation was change in rainfall were 1.37 times more likely to use different enterprise as compared to households who did not expect change in rainfall, keeping other variables in the model constant.

3.4.3. Changing Planting Dates (CPD). The result of Poisson regression model revealed that age of household head, source of information, distance of input market, distance of output market, agroecological location of farm, size of farm, number of livestock, grade of farm, distance of farm, extension service, farmer-to-farmer extension, credit service, rainfall expectation, and temperature expectation were statistically significant factors for changing planting dates as adaptation option to climate change (Appendix 1 Table 5).

3.4.4. Planting Trees (PT). Results in Appendix 1 Table 6 provide estimates of the effect of some selected variables on planting trees as adaptation strategy to climate change. The factors such as age of household head, source of information, household size, educational levels of household head, agroecological location of the farm, size of the farm, grade of the farm, distance of the farm, extension service, farmer-to-farmer extension, rainfall expectation, and temperature expectation were significant factors for planting trees as adaptation option to climate change at $5 \%$ level of significance.

3.4.5. Soil-Water Conservation (SWC) Techniques. The negative binomial regression analysis revealed that age of household head, source of information, education level of household head, agroecological location of the farm, tropical livestock unit, size of the farm, distance of the farm, extension service, farmer-to-farmer extension, rainfall expectation and temperature expectation were significant factors for soil-water conservation technique as adaptation 
option to climate change at $5 \%$ level of significance (Appendix 1 Table 7).

\subsection{Assessment of Goodness of Fit of Multinomial Logistic} Regression, Poisson Regression, and Negative Binomial Regression Analysis. Variance inflation factor of all variables was less than 10 which shows there is no multicollinearity problem. Multicollinearity among the dichotomous variable was tested using Contingency Coefficient (C). As a rule C value of 1 indicates higher association and a value of 0 indicates no association. In the current study, the test result has indicated that there is no serious problem of association among the dichotomous variables included in the model.

\subsubsection{Model Diagnostic Checking for Outliers and Influential} Observations. In general, model diagnostic of the fitted regression model implied that the model fits the data well. The adequacy of the fitted model was checked for possible presence and treatment of outliers and influential values. The DFBETAs for model parameters including the constant term and Cook's influence statistics were both less than unity. DFBETAs less than unity implies no specific impact of an observation on the coefficient of a particular predictor variable while Cook's distance less than unity showed that an observation had no overall impact on the estimated vector of regression coefficients $(\widehat{\beta})$

\subsubsection{Likelihood-Ratio Test of Overall Multinomial Logistic} Regression. The likelihood-ratio test is based on deviance which is the difference between two times likelihood of empty and full model [ $-2 \log$ likelihood (LL)]. As shown in Table 4, the chi-square values were 942.791 with $P$ value 0.0001 which was less than 0.05 level of significance, indicating an evidence against the null hypothesis. So, the conclusion drawn based on multinomial logistic regression analysis including all indicators of adaptation strategies is appropriate.

\subsubsection{Likelihood-Ratio Test of Overall Poisson Regression and} Negative Binomial Model. The likelihood-ratio test is based on deviance which is the difference between two times likelihood of empty and full model [-2 log likelihood (LL)]. Accordingly, all the models adequately fit the data at 0.05 level of significance $(P<0.0001)$. In other words, at least one $\beta$ is significantly different from zero in all models. So, the conclusions made based on all four count models including all indicators are appropriate.

\section{Discussion of Results}

This study aimed to model adaptation preference of farmers in response to climate change in Dera District, Ethiopia, based on data collected from four rural kebeles of the district. The details of discussion for the result obtained from above models are given below. This study revealed that about $44.2 \%, 29.1 \%, 9.3 \%$, and $9.8 \%$ of the respondents preferred planting trees, using different enterprise, changing planting dates, and soil-water conservation techniques, in response to
TABle 4: Model fitting information.

\begin{tabular}{lccccc}
\hline Model & \multicolumn{3}{c}{ Model fitting criteria } & \multicolumn{2}{c}{$\begin{array}{c}\text { Likelihood-ratio } \\
\text { tests }\end{array}$} \\
& AIC & BIC & $\begin{array}{c}-2 \text { log } \\
\text { likelihood }\end{array}$ & $\begin{array}{c}\text { Chi- } \\
\text { square }\end{array}$ & Sig. \\
\hline $\begin{array}{l}\text { Intercept } \\
\text { only }\end{array}$ & 1264.008 & 1280.533 & 1256.008 & 942.761 & 0.0001 \\
Final & 521.247 & 950.895 & 313.247 & & \\
\hline
\end{tabular}

climate change, respectively. Based on the result of MNL model, each predictor variable is discussed as follows.

Age of household head: the result revealed that age of household head has significant relationship with adaptation measures. Age has both positive and negative effect on adaptation strategies. An increase in age of household heads increases the probability of choosing using different enterprises and changing planting dates as adaptation measure. Similar results were obtained by Di falco et al. [13].

Source of information: source of information about climate change from media increases the likelihood of preferring use of different enterprise, changing planting dates, planting trees, and SWC techniques. Similarly, information from social groups increases the probability of using adaptation measures such as using different enterprises, changing planting dates, planting trees, and watersoil conservation techniques.

Household size: another determinant of farmers' preference for climate change adaptation strategies is the number of household members. Increasing household size increases the likelihood of using adaptation strategies (i.e., using different enterprise, planting trees, and SWC techniques) as an adaptation measure. The probable reasons for positive relationship are due to the fact that adaptation strategies are labor-intensive which is more likely to happen in agriculture. This result is in line with Di Falco et al. [14].

Educational level: educational level's coefficient has a positive and significant relationship for preferring watersoil conservation techniques and for planting trees. The probable reason for the positive relationship is due to the fact that educated farmers have more knowledge to combat effects of climate change and also educated person is more likely to adopt improved methods and expected to be more efficient to understand and obtain new technologies than less-educated people.

Distance to market: a unit increase in distance of market decreases the likelihood of choosing using different enterprises and changing planting dates. Indeed, this is in line with the real life; i.e., Households getting easy access to market have a chance of getting access to sell their product, exchange information, and diversify their livelihood easily.

Number of livestock: tropical livestock unit has positive and significant impact on the probability of choosing using different enterprises and soil-water conservation techniques as adaptation strategies. This is because the livestock plays a very important role by serving as a source of income in order to purchase improved crop enterprise and by providing traction (especially oxen) and manure required for soil fertility maintenance. 
Size of the farm size: size of the farm has a significant positive relation with the probability of choosing using different enterprise, changing planting dates, and planting trees as an adaptation measure. This confirms the result of a study by Gbetibouo and Rashid [15].

Access to credit: access to credit increases the likelihood of choosing soil-water conservation as an adaptation measure. This is due to the fact that better access to credit increases financial resources of the farmers which enables farmers to buy all necessary farm inputs. Similar findings were obtained by Fatuase [16].

Access to extension services: access to extension services has a significant and positive relationship with choosing adaptation measure such as using different enterprise, changing planting dates, planting trees, and SWC techniques. This result is in line with the result of Nhemachena et al. [3].

Farmers-to-farmers extension: Access to farmer-to-farmer extension has a positive and significant impact on the adaptation decision such as using different enterprise, changing planting dates, and planting trees. This is because different farmers have different skills, working habits, and experience.

Expectation of temperature and rainfall: a future expectation of weather has a significant and positive relationship with choosing adaptation measures. Expectation of change in weather increases the probability of preferring use of different enterprise, changing planting dates, planting trees, and SWC techniques. This confirms the result of Nhemachena et al. [3].

4.1. Discussion from Count Regression Model. Before the analysis of data using the Poisson or negative binomial approach, the basic assumption of the Poisson model, that is, equality of the mean and variance of each adaptation strategies, was tested. The results indicated that there was no over-dispersion for using different enterprises and planting trees. Therefore, the final models are fit as Poisson linear model and negative binomial regression with a log link to accommodates the count nature of the response variable.

The results from Poisson count regression analysis revealed that age of household head, source of information, household size, distance of output market, distance of input market, agroecological location of the farm, size of the farm, grade of the farm, distance the farm, extension service, farmer-to-farmer extension, rainfall expectation, and temperature expectation were significant factors for using different enterprises as adaptation options to climate change at $5 \%$ level of significance.

The analysis of Poisson regression also revealed that age of household head, source of information, household size, education level of household head, agroecological location of the farm, size of the farm, grade of the farm, distance the farm, extension service, farmer-to-farmer extension, rainfall expectation, and temperature expectation were significant factors for planting trees as adaptation options to climate change at $5 \%$ level of significance.

Secondly, the result of negative binomial regression revealed that age of household head, distance of input market, agroecological location of the farm, size of the farm, grade of the farm, distance the farm, extension service, farmer-to-farmer extension, credit service, rainfall expectation, and temperature expectation were significant factors for changing planting dates as adaptation option to climate change.

Based on finding of study, age of household head, source of information, education level of household head, agroecological location of the farm, tropical livestock unit, size of the farm, the distance of the farm, extension service, rainfall expectation, and temperature expectation were significant factors for soil-water conservation techniques at $5 \%$ level of significance. This is consistent with the result obtained from multinomial logistic regression.

The combination of these four count regression models gives the same result with multinomial logistic regression taking each dependent variable in count regression as categories in multinomial logistic regression.

\section{Conclusion}

The following conclusions are drawn based on the analysis of the study. The perceptions of farmers about climate change and variability over the past 10 years revealed that over $91.6 \%$ of the respondents perceived temperature to be increasing and $85.5 \%$ of the respondents noticed a decrease in the amount of rainfall over the years. This shows that farmers already perceived climate change.

Different combinations of adaptation measures were applied in the study area and they were grouped into four major adaptation options. These are planting trees, using different enterprises, changing planting dates, and soil-water conservation techniques. Planting trees was the most preferred adaptation strategy while changing planting dates was the least preferred adaptation option in the study area. In general, around $92.4 \%$ of the farmers have taken at least one adaptation measures in response to the changing climatic conditions. The remaining $7.4 \%$ did not take any of the adaptation measures. The analysis of data revealed that age, source of information, household size, education level of household head, distance of output market, distance of input market, agroecological locations of the farm, tropical livestock unit, size of farm, tenure, grade of the farm, distance of the farm, extension service, farmer-to-farmer extension, credit service, irrigation service, rainfall expectation, and temperature expectations are significant predictors of adaptation strategies.

5.1. Recommendations. Based on the findings of the research, the following recommendations were forwarded for reducing the impacts of climate change on agriculture. The government and any concerned bodies should give emphasis to address this issue through paying greater attention to improve infrastructures such as distance to market, distance to farm, source information, irrigation service, and credit service. Policies aimed at promoting farm-level adaptation need to emphasize the crucial role of designing programs to increase business support (credit, irrigation service) as well as providing a way to improve farm specific factors (farm size, tenure, grade of the 
farm, and number of livestock units), providing information on better production techniques and enhancing farmers' awareness of climate change. The planners and decision-makers to enhance farmers' adaptation to climate change should take into account the significant roles of climate expectation and climate forecast information on farmers' practices of climate change adaptation; given the role of information in the farmer's adoption of climate change adaptation strategies, planners and decision-makers should enhance extension services to support farmers in their adaptation efforts.

5.2. Limitations. This research paper was limited to statistical modeling of farmers' preference for adaptation strategies for climate change in the Dera District only.

\section{Abbreviations}

AEZ: Agroecological zone

CPD: Changing planting dates

IIA: Independence of irrelevant alternatives

IPCC: Intergovernmental Panel on Climate Change

NAPA: National Adaptation Programs of Action

NMA: National Meteorological Agency of Ethiopia

OLS: Ordinary least square

PT: $\quad$ Planting trees

SWC: Soil-water conservation

TLU: Tropical livestock unit

UDV: Using different enterprise.

\section{Data Availability}

The data used to support the findings of this study are available from the corresponding author upon request.

\section{Conflicts of Interest}

The authors declare that there are no conflicts of interest.

\section{Authors' Contributions}

All the authors collected the data, analyzed and prepared the manuscript, and read and approved the final manuscript.

\section{Acknowledgments}

The authors are heartily thankful to the Dera District Administration Office for allowing and helping them in the process of data collection.

\section{Supplementary Materials}

Appendix 1 Table 1: the coding and explanation of variables in the model. Appendix 1 Table 2: chi-square test of association. Appendix 1 Table3: result of multinomial logistic regression using STATA 12. Appendix 1 Table 4: result of Poisson's regression using STATA 12 (for UDV). Appendix 1 Table 5: result of negative binomial regression using STATA 12 (CPD). Appendix 1 Table 6: result of Poisson's regression using STATA 12 (PT). Appendix 1 Table 7: result of negative binomial regression using STATA 12 (SWC). (Supplementary Materials)

\section{References}

[1] A. Summary, "Climate change 2014 synthesis report approved summary for policymakers," IPCC, Copenhagen, Denmark, 2014.

[2] B. T. Kassie, Climate Variability and Change in Ethiopia: Exploring Impacts and Adaptation Options for Cereal Production, Wageningen University, Wageningen, Netherlands, 2014.

[3] C. Nhemachena, R. Hassan, and J. Chakwizira, "Analysis of determinants of farm-level adaptation measures to climate change in Southern Africa," Journal of Development and Agricultural Economics, vol. 6, no. 5, pp. 232-241, 2014.

[4] R. Hassan and C. Nhemachena, "Determinants of African farmers' strategies for adapting to climate change: multinomial choice analysis," Continental Africa Climate change and agriculture, vol. 2, no. 1, pp. 83-104, 2008.

[5] T. B. Below, K. D. Mutabazi, D. Kirschke et al., "Can farmers' adaptation to climate change be explained by socio-economic household-level variables?" Global Environmental Change, vol. 22, no. 1, pp. 223-235, 2012.

[6] J. S. Okonya, K. Syndikus, and J. Kroschel, "Farmers' perception of and coping strategies to climate change : evidence from six agro-ecological zones of Uganda," Journal of Agricultural science, vol. 5, no. 8, pp. 252-263, 2013.

[7] Ministry of Finance and Economic Development (MoFED), Growth and Transformation Plan: 2010/11-2014/15, MoFED, Addis Ababa, Ethiopia, 2010.

[8] E. Bryan, T. Deressa, and C. Ringler, "Adaptation to climate change in Ethiopia and South Africa: options and constraints," Environmental Science \& Policy, vol. 12, pp. 413-426, 2009.

[9] S. Sarkar and R. N. Padaria, "Farmers' awareness and risk perception about climate change in coastal ecosystem of West Bengal," Indian Research Journal of Extension Education, vol. 10, no. 2, pp. 32-38, 2010.

[10] G. Tesso, B. Emana, and M. Ketema, "Analysis of vulnerability and resilience to climate change induced shocks in North Shewa, Ethiopia," Agricultural Sciences, vol. 3, no. 6, pp. 871-888, 2012.

[11] D. Hosmer and S. Lemeshow, Applied Logistic Regression, John Wiley \& Sons, New York, NY, USA, 2nd edition, 2000.

[12] J. S. Long and J. Freese, Regression Models for Categorical Dependent Variables Using Stata, Stata Press, College Station, TX, USA, 2nd edition, 2006.

[13] Di Falco and S. Di, "What adaptation to climate change? Evidence from the Nile Basin, Ethiopia," in International Conference on Economics of Adaptation to Climate Change in Low-Income Countries. Ethiopian Development Research Institute and International Food Policy Research Institute, Washington, DC, USA, 2011.

[14] S. Di Falco, M. Veronesi, and M. Yesuf, "Does adaptation to climate change provide food security? A micro perspective from Ethiopia," American Journal of Agricultural Economics, vol. 93, no. 3, pp. 829-846, 2012.

[15] G. A. Gbetibouo and M. Rashid, "Modelling farmers' adaptation strategies for climate change and variability: the case of the Limpopo Basin, South Africa," Agrekon: Agricultural Economics Research, Policy and Practice in Southern Africa, vol. 49, no. 2, 2010. 
[16] A. I. Fatuase, "Climate change adaptation: a panacea for food security in Ondo State, Nigeria," Theoretical and Applied Climatology, vol. 129, no. 3-4, p. 939, 2017. 